\title{
Risk factors for fatal candidemia caused by Candida albicans and non-albicans Candida species
}

\author{
Ming-Fang Cheng, 2,3,4, Yun-Liang Yang5, Tzy-Jyun Yao ${ }^{6}$, Chin-Yu Lin ${ }^{6}$, Jih- \\ Shin Liu ${ }^{6}$, Ran-Bin Tang${ }^{2}$, Kwok-Woon $\mathrm{Yu}^{3}$, Yu-Hua Fan7, Kai-Sheng Hsieh ${ }^{1}$, \\ Monto $\mathrm{Ho}^{8}$ and Hsiu-Jung Lo*8
}

Address: ${ }^{1}$ Department of Pediatrics, Veterans General Hospital-Kaohsiung, Kaohsiung, Taiwan, ${ }^{2}$ Section of Infection Disease, Department of Pediatrics, Taiwan, ${ }^{3}$ Department of Microbiology, Veterans General Hospital-Taipei, Taiwan, ${ }^{4}$ National Yang Ming University, Taipei, Taiwan, ${ }^{5}$ Department of Biological Science and Technology, National Chiao Tung University, Hsinchu, Taiwan, ${ }^{6}$ Division of Biostatistics and Bioinformatics, Miaoli, Taiwan, ${ }^{7}$ Koahsiung Medical University, Kaohsiung, Taiwan and ${ }^{8}$ Division of Clinical Research, National Health Research Institutes, Miaoli, Taiwan

Email: Ming-Fang Cheng - mfcheng@vghks.gov.tw; Yun-Liang Yang - yyang@mail.nctu.edu.tw; Tzy-Jyun Yao - tjyun_yao@yahoo.com; ChinYu Lin - lin09_1999@yahoo.com; Jih-Shin Liu - jihshin@nhri.org.tw; Ran-Bin Tang - rbtang@vghtpe.gov.tw; Kwok-

WoonYu - kwyu@vghtpe.gov.tw; Yu-Hua Fan - yhfan2@vghtpe.gov.tw; Kai-Sheng Hsieh - kshsieh@isca.vghks.gov.tw; Monto Ho - monto@imap.pitt.edu; Hsiu-Jung Lo* - hjlo@nhri.org.tw

* Corresponding author

Published: 07 April 2005

BMC Infectious Diseases 2005, 5:22 doi:10.1/86/1471-2334-5-22
Received: 12 January 2005

Accepted: 07 April 2005

This article is available from: http://www.biomedcentral.com/I47I-2334/5/22

(c) 2005 Cheng et al; licensee BioMed Central Ltd.

This is an Open Access article distributed under the terms of the Creative Commons Attribution License (http://creativecommons.org/licenses/by/2.0), which permits unrestricted use, distribution, and reproduction in any medium, provided the original work is properly cited.

\begin{abstract}
Background: Invasive fungal infections, such as candidemia, caused by Candida species have been increasing. Candidemia is not only associated with a high mortality (30\% to $40 \%$ ) but also extends the length of hospital stay and increases the costs of medical care. Sepsis caused by Candida species is clinically indistinguishable from bacterial infections. Although, the clinical presentations of the patients with candidemia caused by Candida albicans and non-albicans Candida species (NAC) are indistinguishable, the susceptibilities to antifungal agents of these species are different. In this study, we attempted to identify the risk factors for candidemia caused by C. albicans and NAC in the hope that this may guide initial empiric therapy.
\end{abstract}

Methods: A retrospective chart review was conducted during 1996 to 1999 at the Veterans General Hospital-Taipei.

Results: There were 130 fatal cases of candidemia, including 68 patients with C. albicans and 62 with NAC. Candidemia was the most likely cause of death in 55 of the 130 patients (42.3\%). There was no significant difference in the distribution of Candida species between those died of candidemia and those died of underlying conditions. Patients who had one of the following conditions were more likely to have $C$. albicans, age $\geqq 65$ years, immunosuppression accounted to prior use of steroids, leukocytosis, in the intensive care unit (ICU), and intravascular and urinary catheters. Patients who had undergone cancer chemotherapy often appeared less critically ill and were more likely to have NAC.

Conclusion: Clinical and epidemiological differences in the risk factors between candidemia caused by $C$. albicans and NAC may provide helpful clues to initiate empiric therapy for patients infected with $C$. albicans versus NAC. 


\section{Background}

Invasive fungal infections caused by Candida species have increased significantly. They now rank fourth as the most common cause of nosocomial bloodstream infections in the United Stated [1] and the most common one at one major hospital in Taiwan [2]. Candidemia is not only associated with a mortality of about $30 \%$ to $40 \%$ but also extends the duration of hospital stay $[3,4]$ and increases the cost for medical care [5]. In recent years, Candida species associated with candidemia have shifted from Candida albicans to non-albicans Candida species (NAC) [6]. Approximately half of the reported cases of candidemia are now caused by NAC [7-10].

Patients with candidemia usually present an acute septic syndrome that is indistinguishable from bacteremia, but they may also exhibit a more indolent course manifested by fever of unknown origin. Major risk factors for candidemia include intravascular catheters, parenteral hyperalimentation, and broad-spectrum antibiotics. Empirical antifungal agents may be administrated to patients manifested with fever of unknown origin and have above mentioned risk factors, particularly those who have been treated with broad-spectrum antibiotics. The clinical presentation of the patients with sepsis caused by C. albicans and NAC are indistinguishable. However, NAC are often less susceptible to fluconazole than C. albicans is $[7,11,12]$ and may require greater dosage to cure clinically $[13,14]$.

We have conducted a retrospective chart review of patients whose death was associated with candidemia. The goal was to assist decisions to select the most appropriate empirical therapy for patients suspected to have candidemia. The objective was to determine whether specific risk factors could be identified to help selecting those patients who are more likely infected with C. albicans versus NAC.

\section{Methods}

This study was conducted at the Veterans General Hospital-Taipei. This is a 2800-bed teaching hospital with about 69,000 admissions annually [7]. A total of 415 blood isolates of Candida species (one strain per species per patient) were collected from April 1996 to December 1999. During this period 130 patients met the inclusion criteria of having at least one positive blood culture for Candida species within one month prior to the fatal outcome. There were 68 patients infected with C. albicans and 62 with NAC.

Candida species were isolated from blood using BACTEC 860 system (Becton Dickinson, INC, Sparks, MD). The species were identified using API-32C system (bioMerieux Vitek, Inc, St. Louis, MI).

\section{Clinical data}

Clinical data of 130 patients were recorded on standardized forms and analyzed according to age at the time of diagnosis, gender and underlying illnesses. These included cancer, diabetes, immunosuppression accounted to prior use of steroids, systemic antifungal agents, cancer chemotherapy, parenteral nutrition, the presence of central or arterial line, endotracheal tube, and urinary catheter, admission to an intensive care unit (ICU), history of infection or gastrointestinal surgery, hemogram, antifungal management, and cause of death. The predisposing events within one month prior to diagnosis and the laboratory data within seven days prior to obtaining the first positive blood culture were analyzed. To decide that a patient died directly of candidemia or underlying illness, we recoded the causes of death according to the death certificate of the patients.

\section{Statistical analysis}

The statistical significance of association between categorical variables was assessed using the Fisher's Exact Test. The risk factors with $\mathrm{p}$ values $<0.1$ in the univariate analysis were placed in a multivariate analysis using the multiple logistic regression package in the SAS System for Windows V8. Confidence limit of $95 \%$ means that the confidence limit contains the true value of odds ratio with probability of 0.95 . The narrower the confidence limit is, the more accurate the estimate is.

\section{Results}

The population consisted of 130 patients whose death was associated with candidemia. Fifty-five (42.3\%) of these deaths were considered to be directly caused by Candida species. The remaining died of complications of their underlying illness. The distribution of species of the total deaths and those causally related to candidemia is shown in Table 1 . There were no significant differences in causation of death according to species. Interestingly, of the four major species related to candidemia, $61.5 \%$ of the isolated Candida glabrata contributed to mortality, followed by $50 \%$ of Candida parapsilosis, $41.2 \%$ of C. albicans, and $31.3 \%$ of Candida tropicalis.

The demographic and clinical characteristics of the study population categorized according to the presence of $C$. albicans or NAC in the blood are summarized in Table 2. The significant $(p \leq 0.05)$ risk factors on univariate analysis for $C$. albicans candidemia were age $\geqq 65$ years, prior bacterial urinary tract infection, central venous catheter, parenteral nutrition and leucocytosis with white blood cell counts $(\mathrm{WBC}) \geqq 15000 / \mathrm{mm}^{3}$, without significant neutropenia with absolute neutrophil counts (ANC) $\geqq$ $100000 / \mathrm{mm}^{3}$. The significant risk factors for NAC were age $<65$ years, cancer chemotherapy, neutropenia (WBC $<3000 / \mathrm{mm}^{3}$ ) and severe thrombocytopenia (platelet 
Table I: Distribution of Candida species of fatal outcome attributed to disseminated candidemia

\begin{tabular}{|c|c|c|c|c|c|}
\hline \multirow{3}{*}{$\begin{array}{l}\text { species } \\
\text { C. albicans }\end{array}$} & \multirow{2}{*}{\multicolumn{2}{|c|}{$\begin{array}{l}\text { Blood isolates }(\mathrm{N}=130) \\
\% \text { in Number } 130 \text { isolates }\end{array}$}} & \multicolumn{3}{|c|}{ Death directly related to candidemia $(\mathrm{N}=55)$} \\
\hline & & & \multicolumn{2}{|c|}{$\%$ in Number 55 isolates } & \multirow{2}{*}{$\begin{array}{c}\% \text { in species of blood isolates } \\
41.2\end{array}$} \\
\hline & 68 & 52.3 & 28 & 50.9 & \\
\hline non-albicans Candida species & 62 & 47.7 & 27 & 49.1 & 43.5 \\
\hline C. tropicalis & 32 & 24.7 & 10 & 18.2 & 31.3 \\
\hline C. glabrata & 13 & 10.0 & 8 & 14.5 & 61.5 \\
\hline C. parapsilosis & 12 & 9.2 & 6 & 10.9 & 50.0 \\
\hline C. guilliermondii & 2 & 1.5 & I & 1.8 & 50.0 \\
\hline C. peniculosa & 2 & 1.5 & 2 & 3.6 & 100.0 \\
\hline C. famata & $\mathrm{I}$ & 0.8 & 0 & 0 & 0 \\
\hline
\end{tabular}

Table 2: Characteristics of 130 patients who died in association with candidemia

\begin{tabular}{|c|c|c|c|c|c|}
\hline \multirow[t]{2}{*}{ Characteristic } & \multicolumn{2}{|c|}{ C. albicans $(\mathrm{N}=68)$} & \multicolumn{2}{|c|}{$\operatorname{NAC}(\mathrm{N}=62)$} & \multirow{2}{*}{$\begin{array}{l}\text { Fisher's Exact Test } \\
\text { Two-sided P-value }\end{array}$} \\
\hline & No. & $\%$ & No. & $\%$ & \\
\hline Age $\geqq 65$ years old & 56 & 82.4 & 36 & 58.1 & $0.004 *$ \\
\hline MICU & 6 & 8.8 & 10 & 16.1 & 0.286 \\
\hline Medical ward stay & 24 & 35.3 & 32 & 51.6 & $0.077^{*}$ \\
\hline Cancer & 24 & 35.3 & 32 & 51.6 & $0.077^{*}$ \\
\hline Immunosuppressive therapy & 17 & 25 & 7 & 11.3 & $0.069 *$ \\
\hline Bacteremia & 25 & 36.8 & 15 & 24.2 & 0.133 \\
\hline Bacterial urinary tract infection & 23 & 33.8 & 10 & 16.1 & $0.026 *$ \\
\hline Prior antifungal administration & 5 & 7.4 & 9 & 14.5 & 0.259 \\
\hline Catheters within 30 days & 65 & 95.6 & 56 & 90.3 & 0.309 \\
\hline ETT & 35 & 51.5 & 23 & 37.1 & 0.114 \\
\hline CVC & 57 & 83.8 & 41 & 66.1 & $0.025 *$ \\
\hline $\mathrm{AL}$ & 21 & 30.9 & 14 & 22.6 & 0.326 \\
\hline Urinary catheter & 49 & 72.1 & 39 & 62.9 & 0.348 \\
\hline PPN & 50 & 73.5 & 34 & 54.8 & $0.029 *$ \\
\hline Cancer chemotherapy & 5 & 7.4 & 12 & 19.4 & $0.066^{*}$ \\
\hline Corticosteroids & 26 & 38.2 & 18 & 29 & 0.354 \\
\hline ANC & \multicolumn{2}{|c|}{$(N=44)$} & \multicolumn{2}{|c|}{$(N=40)$} & I \\
\hline $\mathrm{ANC} \leqq 1500 / \mathrm{mm}^{3}$ & 2 & 4.5 & 2 & 5 & \\
\hline WBC & \multicolumn{2}{|c|}{$(N=67)$} & \multicolumn{2}{|c|}{$(N=6 I)$} & $0.0004 *$ \\
\hline$\leqq 3000 / \mathrm{mm}^{3}$ & 4 & 6 & 14 & 23 & \\
\hline $3000 / \mathrm{mm}^{3}$ to $5000 / \mathrm{mm}^{3}$ & 35 & 52.2 & 38 & 62.3 & \\
\hline$>15000 / \mathrm{mm}^{3}$ & 28 & 41.8 & 9 & 14.8 & \\
\hline Platelet & \multicolumn{2}{|c|}{$(N=66)$} & \multicolumn{2}{|c|}{$(N=6 I)$} & $0.011 *$ \\
\hline$\leqq 20000 / \mathrm{mm}^{3}$ & 5 & 7.6 & 10 & 16.4 & \\
\hline $20000 / \mathrm{mm}^{3}$ to $100000 / \mathrm{mm}^{3}$ & 20 & 30.3 & 29 & 47.5 & \\
\hline$>100000 / \mathrm{mm}^{3}$ & 41 & 62.1 & 22 & 36.1 & \\
\hline
\end{tabular}

* Factors selected for multivariate analysis. AL, arterial line; ANC, absolute neutrophil count; CVC, central venous catheter; ETT, endo trachial tube; ICU, Intensive care unit; PN, parenteral nutrition; WBC, white blood cell

count $\left.\leqq 20000 / \mathrm{mm}^{3}\right)$. NAC patients were more likely to have cancers and to be located on the medical wards $(\mathrm{p}=$ 0.08 ). When multivariate analysis was employed, the significant risk factors for C. albicans were age $\geqq 65$ years, immunosuppressive therapy, and leucocytosis. Signifi- cant risk factors for NAC were age $<65$ years and location on medical wards, which are shown in Table 3.

\section{Discussion}

Candida albicans remains the most common species causing candidemia, but the proportion caused by NAC is 
Table 3: Multiple regression analysis of risk factors for candidemia caused by Candida albicans vs. non-albicans Candida species

\begin{tabular}{|c|c|c|c|c|}
\hline \multirow[b]{2}{*}{ White Blood Cell (WBC) } & \multirow[t]{2}{*}{ Odds Ratio } & \multicolumn{2}{|c|}{ 95\% confidence Limits } & \multirow{2}{*}{$\begin{array}{l}\text { P-value } \\
0.0202\end{array}$} \\
\hline & & & & \\
\hline$>15000 / \mathrm{mm}^{3}$ vs. $\leqq 3000 / \mathrm{mm}^{3}$ & 5.89 & 1.35 & 25.7 & 0.0184 \\
\hline $300 \mathrm{I}-15000 / \mathrm{mm}^{3}$ vs. $\leqq 3000 / \mathrm{mm}^{3}$ & 1.66 & 0.44 & 6.26 & 0.4549 \\
\hline$>15000 / \mathrm{mm}^{3}$ vs. $300 \mathrm{I}-15000 / \mathrm{mm}^{3}$ & 3.55 & 1.29 & 9.79 & 0.0144 \\
\hline Age65 $(\geqq 65$ vs. $<65)$ & 6.73 & 2.37 & 19.1 & 0.0003 \\
\hline Immunosuppressive therapy & 4.39 & 1.26 & 15.32 & 0.0201 \\
\hline Located on a medical ward & 0.37 & 0.16 & 0.88 & 0.025 \\
\hline
\end{tabular}

increasing [7-10]. Patients with NAC are more likely to require greater dosage of fluconazole to cure clinically $[13,14]$. Thus there is a need to identify patients at risk of NAC candidemia to initiate empirical amphotericin B therapy or high-dose fluconazole.

Krcmery and Barnes have identified the following risk factors for NAC [15]. These include prophylaxis with azole compounds as a risk factor for C. krusei and C. glabrata, neutropenia and bone marrow transplantation for C. tropicalis, and insertion of foreign bodies, neonates, and hyperalimentation for C. parapsilosis [15-18]. In this study we have identified additional risk factors that help distinguish candidemia caused by $C$. albicans and NAC. The most important risk factors for $C$. albicans are the old age, procedures associated with intensive care, and an acute sepsis. The most important risk factors for NAC are cancer chemotherapy in association with leukopenia and thrombocytopenia.

It has been reported that Candida species exhibit a spectrum in the extent of adherence to tissues, which correlates with the pathogenicity in humans and animals [19]. Candida albicans exhibit the greatest capacity to adhere to gingival epithelial cells, followed by $C$. tropicalis and $C$. glabrata [19]. The capacity of yeasts to attach to a wide range inanimate surfaces appears to protect them from immune responses and antimicrobial agents [20]. This may explain why C. albicans is more likely to be associated with central venous catheters in this study.

Conventional methods to eradicate C. albicans rely upon the use of antifungal drugs designed to kill the yeast or arrest its growth. However, removal of intravascular catheters is in fact the most simple and effective method $[21,22]$. Another approach is to design new agents that disrupt adherence of the yeasts to host tissues and catheters.

\section{Conclusion}

It is customary to administer amphotericin B for critically ill patients suspected of having candidemia. More often than not, azoles are used for relatively stable patients. NAC tend to be less susceptible to fluconazole than $C$. albicans is $[7,11,23]$. Thus, greater dosage is needed till the causative microorganism is isolated and identified, particularly with patients at high risk for NAC candidemia. Though, a large, prospective study is needed to validate this concept, the risk factors identified in this study may help, in clinical practice, to differentiate fatal candidemia caused by $C$. albicans versus NAC.

\section{Abbreviations used}

NAC, non-albicans Candida species; VGH-TPE, Veterans General Hospital-Taipei; ICU, intensive care unit; $\mathrm{AL}$, arterial line; ANC, absolute neutrophil count; CVC, central venous catheter; ETT, endo trachial tube; WBC, white blood cell.

\section{Competing interests}

The author(s) declared that they have no competing interests.

\section{Authors' contributions}

MFC conceived the study and designed it together with, YLY, MH, and HJL. MFC conducted the experiments with contribution from RBT, YHF, and KSH. KWY collected clinical isolates. JSL performed the statistical study with contributions from CYL and TJY. MFC drafted the manuscript with contribution from YLY and HJL.

\section{Acknowledgements}

We would like to thank Dr. Calvin M. Kunin and Dr. Clifford L. McDonald for their expert discussion. We would like to thank Mrs. Ing-Ming Liu at VGH-TPE for her help in collecting the isolates. We are also indebted to Mr. Hsiao-Hsu Cheng and Dr. Feng-Jui Chen at the National Health Research Institutes, Miaoli County, Taiwan, for their help in data processing.

\section{References}

I. Jarvis WR: Epidemiology of nosocomial fungal infections, with emphasis on Candida species. Clin Infect Dis 1995, 20:I526-I530.

2. Chen YC, Chang SC, Sun CC, Yang LS, Hsieh WC, Luh KT: Secular trends in the epidemiology of nosocomial fungal infections at a teaching hospital in Taiwan, 1981 to 1993. Infect Control Hosp Epidemiol 1997, 18:369-375. 
3. Leleu G, Aegerter P, Guidet B: Systemic candidiasis in intensive care units: a multicenter, matched-cohort study. J Crit Care 2002, 17:168-175.

4. Wey SB, Mori M, Pfaller MA, Woolson RF, Wenzel RP: Hospitalacquired candidemia: The attributable mortality and excess length of stay. Arch Intern Med I988, I48:2642-2645.

5. Tortorano AM, Caspani L, Rigoni AL, Biraghi E, Sicignano A, Viviani MA: Candidosis in the intensive care unit: a 20-year survey. J Hosp Infect 2004, 57:8-13.

6. Viscoli C, Girmenia C, Marinus A, Collette L, Martino P, Vandercam B, Doyen C, Lebeau B, Spence D, Krcmery V, De Pauw B, Meunier F: Candidemia in cancer patients: a prospective, multicenter surveillance study by the Invasive Fungal Infection Group (IFIG) of the European Organization for Research and Treatment of Cancer (EORTC). Clin Infect Dis 1999, 28: 107I-1079.

7. Cheng MF, Yu KW, Tang RB, Fan YH, Yang YL, Hsieh KS, Ho M, Lo $\mathrm{HJ}$ : Distribution and antifungal susceptibility of Candida species causing candidemia from 1996 to 1999. Diagn Microbiol Infect Dis 2004, 48:33-37.

8. Colombo AL, Nucci M, Salomao R, Branchini ML, Richtmann R, Derossi A, Wey SB: High rate of non-albicans candidemia in Brazilian tertiary care hospitals. Diagn Microbiol Infect Dis 1999, 34:28I-286

9. Kao AS, Brandt ME, Pruitt WR, Conn LA, Perkins BA, Stephens DS, Baughman WS, Reingold AL, Rothrock GA, Pfaller MA, Pinner RW, Hajjeh RA: The epidemiology of candidemia in two United States cities: results of a population-based active surveillance. Clin Infect Dis 1999, 29: I 164-1 I70.

10. Pfaller MA, Jones RN, Doern GV, Sader HS, Messer SA, Houston A, Coffman S, Hollis RJ: Bloodstream infections due to Candida species: SENTRY antimicrobial surveillance program in North America and Latin America, 1997-1998. Antimicrob Agents Chemother 2000, 44:747-75I.

II. Yang YL, Ho YA, Cheng HH, Ho M, Lo HJ: Susceptibilities of Candida species to amphotericin $B$ and fluconazole: the emergence of fluconazole resistance in Candida tropicalis. Infect Control Hosp Epidemiol 2004, 25:60-64.

12. Yang YL, Cheng HH, Lo HJ: In vitro activity of voriconazole against Candida species isolated in Taiwan. Int J Antimicrob Agents 2004, 24:294-296.

13. Nguyen MH, Peacock JE Jr, Morris AJ, Tanner DC, Nguyen ML, Snydman DR, Wagener MM, Rinaldi MG, Yu VL: The changing face of candidemia: emergence of non-Candida albicans species and antifungal resistance. Am I Med 1996, 100:617-623.

14. Redding SW, Kirkpatrick WR, Dib O, Fothergill AW, Rinaldi MG, Patterson TF: The epidemiology of non-albicans Candida in oropharyngeal candidiasis in HIV patients. Spec Care Dentist 2000, 20:178-181.

15. Krcmery V, Barnes AJ: Non-albicans Candida spp. causing fungaemia: pathogenicity and antifungal resistance. J Hosp Infect 2002, 50:243-260.

16. Abi-Said D, Anaissie E, Uzun O, Raad I, Pinzcowski H, Vartivarian S: The epidemiology of hematogenous candidiasis caused by different Candida species. Clin Infect Dis 1997, 24: I I22-I I 28.

17. Kralovicova K, Spanik S, Oravcova E, Mrazova M, Morova E, Gulikova V, Kukuckova E, Koren P, Pichna P, Nogova J, Kunova A, Trupl J, Krcmery $\vee \mathrm{Jr}$ : Fungemia in cancer patients undergoing chemotherapy versus surgery: risk factors, etiology and outcome. Scand J Infect Dis 1997, 29:30I-304.

18. Wingard JR: Importance of Candida species other than C. albicans as pathogens in oncology patients. Clin Infect Dis 1995, 20: II5- 125 .

19. Nikawa H, Egusa $\mathrm{H}$, Makihira S, Nishimura M, Ishida K, Furukawa M, Hamada T: A novel technique to evaluate the adhesion of Candida species to gingival epithelial cells. Mycoses 2003, 46:384-389.

20. Yang YL, Cheng HH, Ho YA, Hsiao CF, Lo HJ: Fluconazole resistance rate of Candida species from different regions and hospital types in Taiwan. J Microbiol Immunol Infect 2003, 36:187-I91.

21. Fatkenheuer G, Buchheidt D, Cornely OA, Fuhr HG, Karthaus M, Kisro J, Leithauser M, Salwender H, Sudhoff T, Szelenyi H, Weissinger F: Central venous catheter (CVC)-related infections in neutropenic patients - guidelines of the Infectious Diseases Working Party (AGIHO) of the German Society of Hema- tology and Oncology (DGHO). Ann Hematol 2003, 82(Suppl 2):S149-57. Epub@2003 Sep 9.: SI49-SI57.

22. Salvaggio MR, Pappas PG: Current Concepts in the Management of Fungal Peritonitis. Curr Infect Dis Rep 2003, 5: I20-I 24.

23. Pfaller MA, Messer SA, Boyken L, Hollis RJ, Rice C, Tendolkar S, Diekema DJ: In vitro activities of voriconazole, posaconazole, and fluconazole against 4, 169 clinical isolates of Candida spp. and Cryptococcus neoformans collected during $200 \mathrm{I}$ and 2002 in the ARTEMIS global antifungal surveillance program. Diagn Microbiol Infect Dis 2004, 48:20I-205.

\section{Pre-publication history}

The pre-publication history for this paper can be accessed here:

http://www.biomedcentral.com/1471-2334/5/22/prepub
Publish with Biomed Central and every scientist can read your work free of charge

"BioMed Central will be the most significant development for disseminating the results of biomedical research in our lifetime. "

Sir Paul Nurse, Cancer Research UK

Your research papers will be:

- available free of charge to the entire biomedical community

- peer reviewed and published immediately upon acceptance

- cited in PubMed and archived on PubMed Central

- yours - you keep the copyright

Submit your manuscript here:

http://www.biomedcentral.com/info/publishing_adv.asp 